\title{
Research on Comprehensive Evaluation of Enterprise's Technological Innovation Talent Team by Using Analytic Network Process (ANP) and Grey Related Analysis
}

\author{
Ying Wang, Yan Liu \\ School of Management, Changchun University \\ 6543 Weixing Road ,Changchun,Jilin Province,China \\ yan1126@tom.com
}

\begin{abstract}
The source of innovation is the technological talent .This paper established the indicator system of evaluation of enterprise's technological innovation talent team . It used ANP to determine the weight of indicators and grey related analysis to determine the rank ordering of enterprises. It provides the theoretic and decision foundation for the technological innovation talent environment construction and technological innovation talent cultivation model optimization.
\end{abstract}

Kewords- Technological innovation talent; Evaluation indicator system; ANP; Grey related analysis

\section{INTRODUCTION}

In modern times,the technological innovation talent and the innovation capability are the valuable resources.Building a strong technological innovation talent team is key to sustaining development of enterprises.Without the effective technological innovation talent team,enterprises can not be successful.By reading materials,we can find a lot of papers are related to the technological innovation talent education and cultivation.But the research on the construction of the indicator system of evaluation of enterprise's technological innovation talent team,comprehensive evaluation of technological innovation talent team are limited.In fact,there are some problems in construction of enterprise's technological innovation talent team in China.

Therefore,it is necessary to evaluate the technological innovation talent team and analyse the influential factors.The paper will make enterprises know the key factors of influence and it is useful for reference in the construction of technological innovation talent team.

\section{ANP AND GREY RELATED ANALYSIS IN COMPREHENSIVE EVALUATION OF ENTERPRISE'S TECHNOLOGICAL INNOVATION TALENT TEAM}

\section{A. Analytic Network Process}

The initial study identified the multi-criteria decision technique known as the Analytic Hierarchy Process(AHP) to be the most appropriate for solving complicated problems.AHP was proposed by Saaty in 1980 as a method of solving socio-economic decision making problems and has been used to solve a wide range of problems[1]

Generally,we solve complex problems by discussing them with team members.However,when we do not know the exact relationship in the network structure or the degree of interdependence among considering criteria,it is dangerous to determine by one or two decision makers.ANP is the most important function to determine the relationship of a network structure or the degree of interdependence.The steps are as follows[2]:

Step1:in this step the interactions between and within clusters and elements are determined.

Step2:in this step supermatrix is constructed according to the network built in step1.The priority vectors derived from pairwise comparison matrices are each entered as a part of some column of a supermatrix. The supermatrix represents the influence priority of an element on the left of the matrix on an element at the top of the matrix.

Step3: the supermatrix needs to be stochastic to derive meaningful limiting priorities. So for this reason to get the weighted supermatrix, firstly the influence of the clusters on each cluster with respect to the control criterion is determined. This yields an eigenvector of influence of the clusters on each cluster. Then the unweighted supermatrix is multiplied by the priority weights from the clusters, which yields the weighted supermatrix.

Step4: finally the supermatrix will be steady state by multiplying the weighted supermatrix by itself until the supermatrix's row values converge to the same value for each column of the matrix.

\section{B. Grey Related Analysis}

The grey relational analysis method, which is a basic method of grey system theory for systems analysis, is based on qualitative analysis and quantitative analysis. The steps are as follows[3]:

Step1:determine reference number Sequence $X_{0}$ and alternative number sequence $X_{i}$

$$
\begin{gathered}
X_{0}=\left(X_{01}, X_{02}, \cdots, X_{0 n}\right) ; X_{i}=\left(X_{i 1}, X_{i 2}, \cdots, X_{i n}\right)(i=1,2, \cdots, m) \\
\text { Step2:determine connection coefficient } \xi_{i k} \\
\xi_{i k}=\frac{\min _{i} \min _{k}\left|X_{0 k}-X_{i k}\right|+\rho \max _{i} \max _{k}\left|X_{0 k}-X_{i k}\right|}{\left|X_{0 k}-X_{i k}\right|+\rho \max _{i} \max _{k}\left|X_{0 k}-X_{i k}\right|} \\
(i=1,2, \cdots, m ; k=1,2, \cdots, n)
\end{gathered}
$$

Step3:determine connection degree

After calculating $\xi_{i k}$,the connection between alternative and reference number sequence will be calculated according to the following formula

$$
r_{i}=\frac{1}{n} \sum_{k}^{n} \xi_{i k}, \quad \mathrm{i}=1,2, \ldots, \mathrm{m}
$$


Step4:determine optimal alternative

The feasible alternative ${ }_{X_{t}}$ is optimal by grey related analysis if $r_{t}=\max _{1 \leq i \leq m} r_{i}$

\section{Establishment of Indicator System of Enterprise's Technological Innovation Talent Team}

According to theoretical analysis method, through the analysis of characteristics of enterprise's technological innovation talent, we choose indicators from the perspective of strategic management of technological innovation talent team.This paper gives six criteria,nineteen sub-criteria and forty-eight alternatives.The structure of the model is described by its clusters and elements, and by the connection between them.These connections indicate the influence between the elements.

We select high frequency indicators.Based on this, indicator system can be established. Through the collation of literatures and experts' advice, we can establish a series of indicators from six main categories:Total indicators and relative indicators $\mathrm{C}_{1}$, Structure indicators $\mathrm{C}_{2}$, Quality indicators $\mathrm{C}_{3}$,Turnover indicators $\mathrm{C}_{4}$ Efficiency indicators $\mathrm{C}_{5}$,Environmental indicators $\mathrm{C}_{6}$, as shown in Table $\mathrm{I}$.

Table I Indicator System of Comprehensive Evaluation of Enterprise's Technological Innovation Talent Team

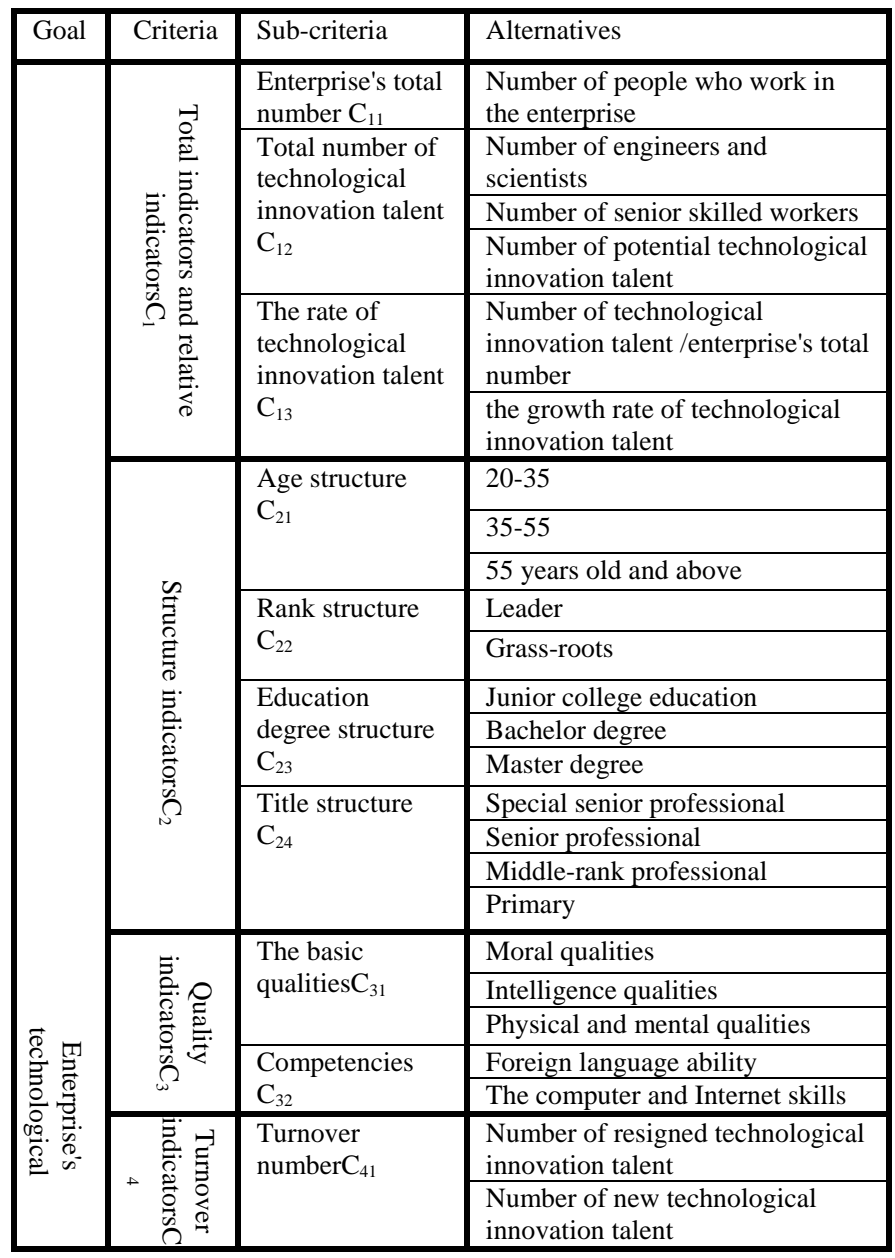

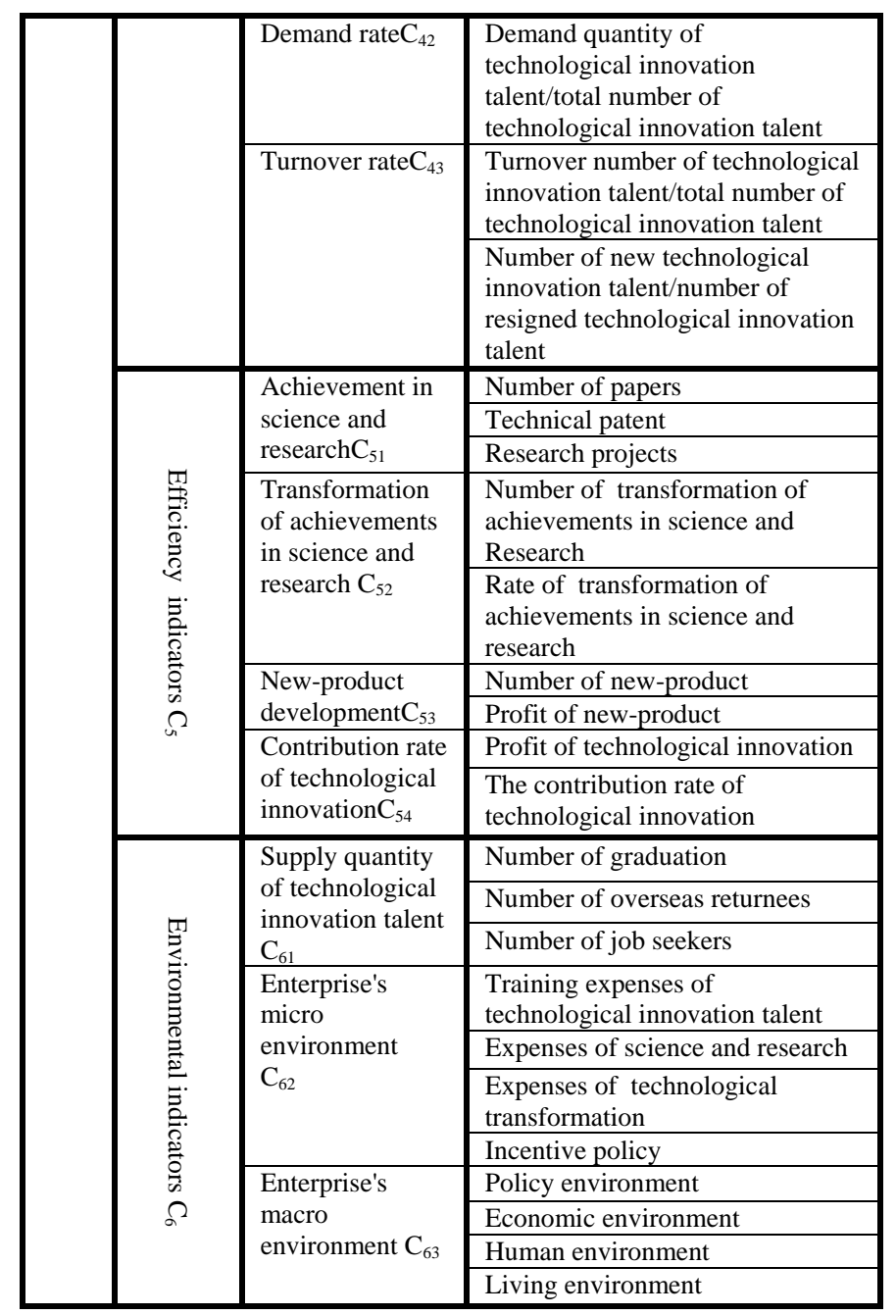

\section{Internal Relationship Structure of Evaluation Indicator System}

The six criteria are not independent,there are interaction effects between them.The structure connections of mutual influence and self feedback can be illustrated by the ANP structure principle.The net structure given by Fig.1 is called out dependence.

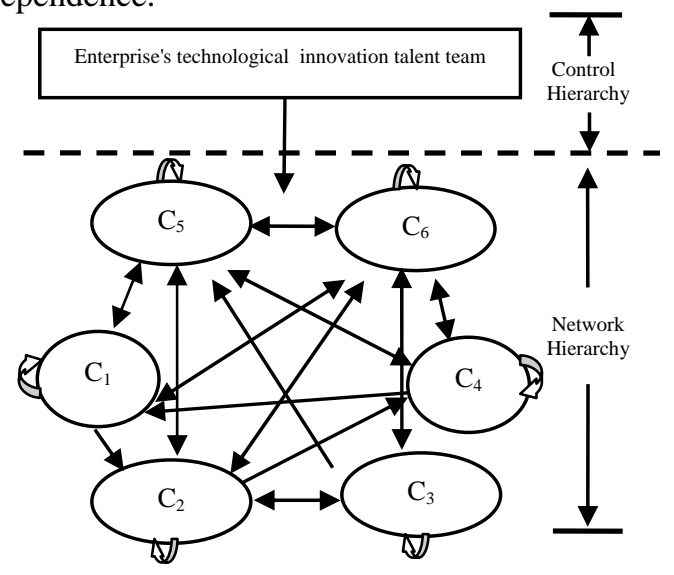

Fig.1. Connections in a Network 


\section{E. The Supermatrix and The Weights}

A supermatrix is a two-dimensional matrix of elements by elements. The priority vectors from the paired comparisons appear in the appropriate column of the supermatrix. In the supermatrix, the sum of each column corresponds to the number of comparison sets[4]. All the numbers which corresponds to the influence of the ${ }_{C_{i}}$ cluster on the left on the $C_{C_{i}}$ cluster at the top are multiplied by the weight of the cluster ${ }_{C_{i}}$. Applying the cluster matrix numbers to their respective blocks in the unweighted supermatrix yields the weighted matrix that is column stochastic.Finally,we get the weights of criteria and subcriteria of technological innovation talent team[5],as shown in Table II.

We can conclude according to Table II:

1)The weight of environmental indicators is the first, $\varpi_{6}=0.4460$; next is efficiency indicators, $\varpi_{5}=0.2732$; the third one is quality indicators, $\varpi_{3}=0.1122$; the fourth one is turnover indicators, $\varpi_{4}=0.0782$; the fifth one is total indicators and relative indicators, $\varpi_{1}=0.0502$; the weight of structure indicators is final, $\varpi_{2}=0.0402$.

2)The environmental indicators are most important.It not only includes the incentive policy and the input for the technological innovation,but also includes supply quantity of technological innovation talent and policy support.They have impact on every indicator directly and are critical to the evaluation object.

3)The second one is efficiency indicators.For evaluating the strength of technological innovation talent team,efficiency indicators are direct way.No matter horizontal comparison among enterprises or vertical comparison among each enterprise itself,achievement in science and research,new-product development and contribution rate of technological innovation are key indicators in evaluating technological innovation talent team.

4)Quality indicators can not be overlooked.To enhance the capability of technological innovation,establishing a efficiency technological innovation talent team is important for enterprises.

Table II Weights of Technological Innovation Talent Team

\begin{tabular}{|c|c|c|c|c|}
\hline Goal & Criteria & Weights & Sub-criteria & Weights \\
\hline \multirow{13}{*}{ 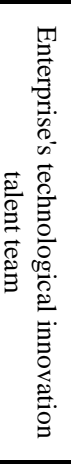 } & \multirow{3}{*}{$\mathrm{C}_{1}$} & \multirow{3}{*}{0.0502} & $\mathrm{C}_{11}$ & 0.0059 \\
\hline & & & $\mathrm{C}_{12}$ & 0.0154 \\
\hline & & & $\mathrm{C}_{13}$ & 0.0289 \\
\hline & \multirow{4}{*}{$\mathrm{C}_{2}$} & \multirow{4}{*}{0.0402} & $\overline{C_{21}}$ & 0.0004 \\
\hline & & & $\mathrm{C}_{22}$ & 0.0083 \\
\hline & & & $\mathrm{C}_{23}$ & 0.0069 \\
\hline & & & $\mathrm{C}_{24}$ & 0.0246 \\
\hline & \multirow{2}{*}{$\mathrm{C}_{3}$} & \multirow{2}{*}{0.1122} & $\mathrm{C}_{31}$ & 0.0320 \\
\hline & & & $\mathrm{C}_{32}$ & 00801 \\
\hline & \multirow{3}{*}{$\mathrm{C}_{4}$} & \multirow{3}{*}{0.0782} & $\mathrm{C}_{41}$ & 0.0194 \\
\hline & & & $\mathrm{C}_{42}$ & 0.0242 \\
\hline & & & $\mathrm{C}_{43}$ & 0.0346 \\
\hline & $\mathrm{C}_{5}$ & 0.2732 & $\mathrm{C}_{51}$ & 0.0263 \\
\hline
\end{tabular}

\begin{tabular}{|c|c|c|c|c|}
\hline \multirow{2}{*}{} & & $\mathrm{C}_{52}$ & 0.0440 \\
\cline { 3 - 4 } & & $\mathrm{C}_{53}$ & 0.0785 \\
\cline { 3 - 4 } & & $\mathrm{C}_{54}$ & 0.1244 \\
\hline \multirow{3}{*}{$\mathrm{C}_{6}$} & \multirow{3}{*}{0.4460} & $\mathrm{C}_{61}$ & 0.0221 \\
\cline { 3 - 4 } & & $\mathrm{C}_{62}$ & 0.2933 \\
\cline { 3 - 4 } & & $\mathrm{C}_{63}$ & 0.1307 \\
\hline
\end{tabular}

5)Turnover indicators have influence on the long-term development of enterprise's technological innovation talent

team.The turnover of talent reflects enterprise's vitality and human resource policy.A stable technological innovation talent team is critical to enterprise's success.

6)Without the support of absolute quantity of employees,enterprises can not establish a high quality,high efficiency and high level technological innovation talent team.Although the total indicators and relative indicators can influence the efficiency of the team,the restraint is very limited.But we can not overlook them.

7)Reasonable structure can promote the efficiency of technological innovation talent team on the premise of good and open environment,high quality technological innovation talent and a stable team.So the weight comes bottom.

\section{EXAMPLE}

Here, we shall analyse the following example with the method of grey related analysis.We regard the optimal value of indicators of investigated enterprises' technological innovation talent team as corresponding elements $v_{0 k}(k=0,1, \cdots, n)$ of reference number sequence $v_{0}$, the indicators of the enterprises which are evaluated as corresponding elements $\mathrm{v}_{i k}(i=1,2, \cdots, m ; k=1,2, \cdots, n)$ of alternative number sequence $\mathrm{V}_{i}$. We should determine the connection degree $R_{i}$ 。 The rank ordering of the connection degree $R_{i}$ is the rank ordering of superior or inferior in strength of enterprise's technological innovation talent team.

According to Table II,we can know the weight of indicators.But because of the incomparability of data,the indicators of enterprise's total number $C_{11}$, total number of technological innovation talent $\mathrm{C}_{12}$, turnover number $\mathrm{C}_{41}$, supply quantity of technological innovation talent $\mathrm{C}_{61}$ are not included for statistical analysis.We should determine the weight of each indicator by using ANP again.

We choose eight enterprises in Jilin Province as data samples.Then we calculate alternative number sequence and reference number sequence.Using(1), the connection coefficient $\xi_{\mathrm{ik}}(\mathrm{i}=1,2, \cdots, 8 ; \mathrm{k}=1,2, \cdots, 15)$ is then calculated and arranged matrix $\mathrm{E}_{8 \times 15}$, as shown in Table III.

By these results,we know that the connection between every alternative and reference number sequence is,respectively

$\mathrm{R}_{\mathrm{A}}=\left(\mathrm{r}_{1}, \mathrm{r}_{2}, \cdots, \mathrm{r}_{6}\right)=(0.2625,0.2585,0.2753,0.2563,0.2304,0.2$ $508,0.2750,0.2608$ )

We rank feasible alternatives from largest to smallest.The rank ordering of feasible alternatives is $\mathrm{C}>\mathrm{G}>\mathrm{A}>\mathrm{H}>\mathrm{B}>\mathrm{D}>\mathrm{F}>\mathrm{E}$.

Here the rank ordering implies that enterprise $C$ has the 
highest connection degree, it is 0.2753 ,that means enterprise $\mathrm{C}$ is the best one among the eight enterprises.

According to Table III,the connection coefficient of some key indicators such as enterprise's micro environment ,macro environment, contribution rate of technological innovation and age structure of enterprise $\mathrm{C}$ reach or nearly reach largest value 1 .That is to say,enterprise $\mathrm{C}$ invests more in technological innovation than other enterprises.Enterprise $\mathrm{C}$ has good policy in technological innovation talent team construction.But in terms of enterprise E,the connection coefficient of indicators is lower than other enterprises,that is to say,enterprise E should make more effort in enhancing the quality of technological innovation talent team.

Table III Connection Coefficient $\left({ }^{E_{8 \times 15}}\right)$

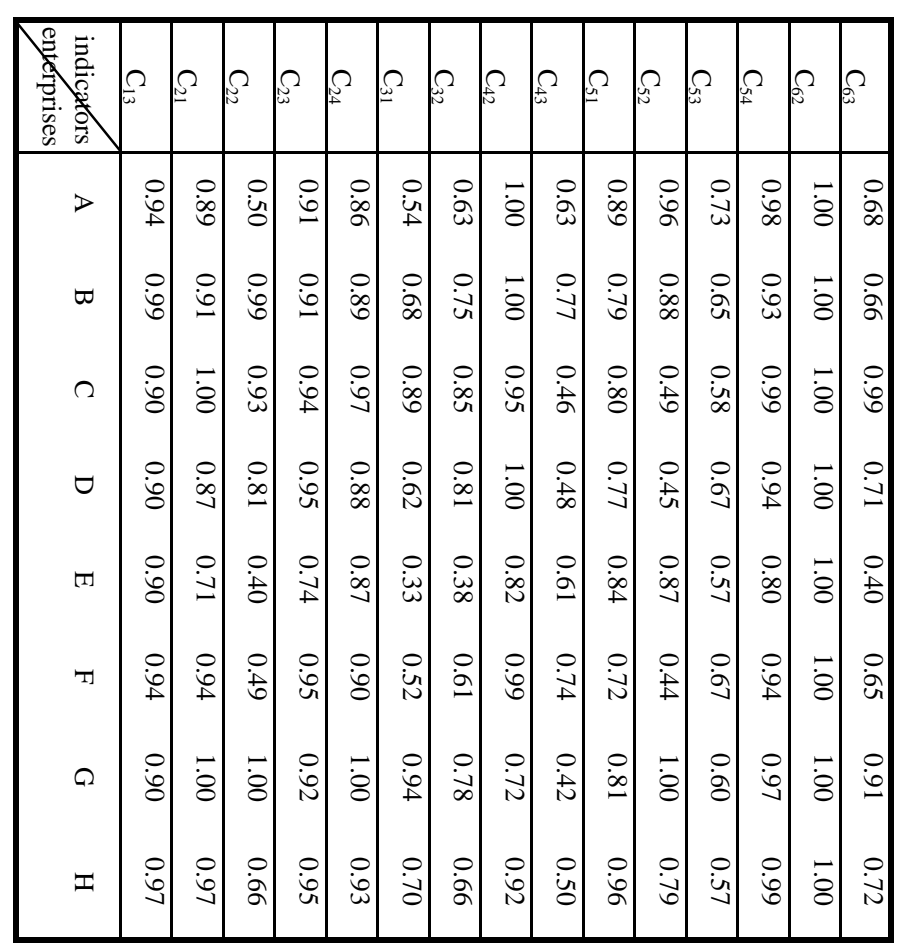

IV. CONCLUSION

The comprehensive evaluation of enterprise's technological innovation talent team is an important problem to enterprises.We first establish the indicator system, and then determine the weight of every indicator by using ANP approach.Finally,the paper rank the enterprises in the order by using grey related analysis approach.Through the adoption of theoretical research and empirical analysis methods, we can conclude:

1) The evaluation of enterprise's technological innovation talent team is creation of the combining powers.Enterprises have to make effort in various aspects in order to improve their strength in technological innovation talent team.

2) The indicator system of technological innovation talent team is a dynamic system.

3) In the system,environmental indicators are important, next are efficiency indicators, quality indicators,turnover indicators, total indicators and relative indicators and structure indicators.

4) The indicators in the system are not independent. They interacts and are attached to one another.So the application of the ANP is desirable.

5) Enterprises can make horizontal comparison among enterprises and horizontal vertical among each enterprise in the development of technological innovation talent team by using grey related analysis. Enterprises can also improve the indicators which have low correlation degree and then enhance the strength of technological innovation talent team.

\section{ACKNOWLEDGMENT}

The material for this paper was extracted from research subject on"Comprehensive Evaluation of Enterprise's Technological Innovation Talent Team In Jilin Province".The authors would like to thank the respondents who provided data.

\section{REFERENCES}

[1] Saaty, T.L., "Decision-Making - The Analytic Hierarchy and Network Processes (AHP/ANP)”, JSSSE, January 2004.

[2] Cevriye Gencer *, Didem Gurpinar, Analytic network process in supplier selection: A case study in an electronic firm,Applied Mathematical Modelling 31 (2007) 2475-2486

[3] Jijun Zhang,Desheng Wu,D. L. Olson,The Method of Grey Related Analysis to Multiple Attribute Decision Making Problems with Interval Numbers, Mathematical and Computer Modelling (2005)

[4] Sanjay Jharkharia,Ravi Shankar,Selection of logistics service provider: An analytic network process (ANP) approach,the international journal of management science(2007)

[5] T.L.Saaty. Fundamentals of the Analytic Network Process-dependence and Feedback in Decision-making with a Single Network[J].Journal of Systems Science and Systems Engineering.2004(6):129-157 